\title{
As representações do outro na investigação das coleções sertanejas do MAE-USP
}

\section{The representations of the other in the investigation of wilderness collections housed at MAE-USP}

\author{
Bianca Gonçalves de Souza'
}

DOI 10.265 I2/museologia.v9i I8.26384

\begin{abstract}
Resumo:
Esse artigo discute como se dá a representação do outro por meio de coleções museológicas. Limita-se às coleções abrigadas no Museu de Arqueologia e Etnologia da Universidade de São Paulo, MAE-USP, denominadas coleções sertanejas. Tais coleções são compostas de artefatos que se ligam a um espaço e a um tempo que outrora representava um Brasil desconhecido e inóspito às pessoas das cidades. $O$ artigo é um desdobramento de pesquisa em andamento, tem caráter empírico e bibliográfico, com levantamento e consulta de fontes documentais, que colaborem para o entendimento do universo pesquisado.
\end{abstract}

Palavras-chave:

Representações do outro. Sertanejo. Coleções sertanejas. Práticas de colecionar. Classificar e organizar objetos.

\begin{abstract}
:
This article discusses how the other is represented through museum collections. It is limited to collections housed at the Museum of Archeology and Ethnology of the University of São Paulo, MAE-USP, called collections came from wilderness. Such collections are composed of artifacts that are linked to a space and a time that once represented an unknown and inhospitable Brazil to the people of the cities. The article is an offshoot of research in progress, has empirical and bibliographic character, with survey and consultation of documentary sources, which contribute to the understanding of the researched universe.
\end{abstract}

\section{Keywords}

Representations of the other. Man who lived in wilderness lands. Wilderness collections. Practices of collecting. Classifying and organizing objects.

\section{Introdução}

O sertão vai virar mar

Dá no coração

O medo que algum dia

O mar também vire sertão

(Sá e Guarabira)

Vários são os trabalhos no Brasil que discutem as questões sobre o chamado sertão. Todas elas sempre tratam essa referência como algo maior que uma questão meramente geográfica; sempre fazem alusão aos modos de vida, às práticas culturais e aos meios com os quais esses sujeitos que viviam longe das cidades grandes lidavam com o meio natural e com os grupos nos quais viviam. $\mathrm{Na}$ própria literatura nacional, há uma referência famosa feita pelo escritor Euclides da Cunha, em seu livro chamado Os Sertões ${ }^{2}$, no qual retratou a realidade

I Pós-doutoranda do Programa de Pós-Graduação Interunidades em Museologia da Universidade de São Paulo/Museu de Arqueologia e Etnologia-MAE. Bolsista do PNPD/CAPES. Contato: biancagsouza@yahoo. com.br 
do sertanejo nordestino, em tempos da revolta de Canudos. Euclides entendia o sertanejo como um homem forte, resistente e resiliente, capaz de sobreviver em condições bastante adversas, como a seca e a pobreza extrema. Também Guimarães Rosa, em Grande Sertão:Veredas ${ }^{3}$, revela em seus personagens nordestinos que habitavam cantões do interior dos estados da região Nordeste e do estado de Minas Gerais, e que em suas figuras sempre revelavam homens e mulheres sofridos e acostumados com as agruras do sertão. Sua personagem principal, Riobaldo, fala que o sertão era ele mesmo, pois enfrentava - durante sua jornada como jagunço - dilemas internos e de autoconhecimento.

Vale mais a pena tratar essa realidade como sertões, no plural, visto que trata sempre de espaços interioranos, porém bastante diversos entre si: o Nordeste brasileiro difere muito do interior de Minas Gerais e de São Paulo, que tratavam como sertões terras longínquas e não desbravadas pelo homem branco e civilizado, sendo muitas vezes habitadas por índios bravios e incivilizados.

A proposta desse artigo é refletir a respeito da figura do sertanejo, especialmente daquele que vivia em rincões do Estado de São Paulo. Essa perspectiva de análise se dá através da reflexão de coleções museológicas que abraçam objetos conhecidos como sertanejos, e que revelam um pouco a respeito do modo de vida desses indivíduos, em especial durante o final do século XIX e início do século XX. Em expedições realizadas por desbravadores e por pesquisadores, tais objetos foram reunidos no acervo do Museu Paulista em São Paulo, capital. A função de coleções museológicas é sempre colaborar para conhecermos melhor o mundo no qual vivemos, práticas culturais, sociais, econômicas; a cultura material é um caminho que favorece o conhecimento desse outro conhecido como sertanejo, e que era tão diferente e distante do modo de vida dos cidadãos de grandes cidades, como a capital paulista.

Atualmente, parte dessas coleções sertanejas está na reserva técnica do Museu de Arqueologia e Etnologia da Universidade de São Paulo. São objetos oriundos de um acervo inicial reunido no Museu Paulista, pertencente à mesma universidade. Interessa aqui, entretanto, refletir com o auxílio do acervo localizado no MAE-USP, com base em documentação museológica que trata de tais coleções e com o auxílio de bibliografia especializada, a fim de corroborar o entendimento a respeito dessa figura tão brasileira, que é o sertanejo paulista.

\section{Os sertões pelo Brasil afora}

Apesar de a denominação sertanejo, na maior parte das vezes, se referir ao indivíduo que vivia e vive na região Nordeste do Brasil, a palavra foi apropriada e utilizada de forma corriqueira para se referir a grupos humanos de outras regiões do país. Darcy Ribeiro (1995), quando fala a respeito do Brasil sertanejo, delimita-o geograficamente às terras de solo massapé, áreas que abrigaram os engenhos de açúcar do período colonial. Ele delimita a região sertaneja entre a área úmida do agreste nordestino, avançando para as regiões semiáridas, até atingir o Brasil central, atingindo a região dos cerrados (RIBEIRO, 1995).

A região fora basicamente movida pela atividade de pastoreio, o que fez surgir figuras importantes nesse cenário, como o vaqueiro. Todavia, tratava-se de uma área dominada por poucos proprietários de terra e uma imensa população de pobres, sem formação e sem educação formal, e que possuíam poucas oportunidades de trabalho, especialmente na região Nordeste, onde a

3 A primeira edição é de 1946. 
industrialização não se instalou. $\bigcirc$ extrativismo, o trabalho agrícola e a mineração (em certas localidades, como em Minas Gerais), eram as poucas opções de sobrevivência para o homem sertanejo (RIBEIRO, 1995).

\begin{abstract}
As populações sertanejas, desenvolvendo-se isoladas da costa, dispersas em pequenos núcleos através do deserto humano que é o mediterrâneo pastoril, conservaram muitos traços arcaicos. (...). $\bigcirc$ sertanejo arcaico caracteriza-se por sua religiosidade singela tendente ao messianismo fanático, por seu carrancismo de hábitos, por seu laconismo e rusticidade, por sua predisposição ao sacrifício e à violência. $E$, ainda, pelas qualidades morais características das formações pastoris do mundo inteiro, como o culto da honra pessoal, o brio e a fidelidade a suas chefaturas. Esses traços peculiares ensejaram muitas vezes o desenvolvimento de formas anônimas de conduta que envolveram enormes multidões, criando problemas sociais da maior gravidade. Suas duas formas principais de expressão foram o cangaço e o fanatismo religioso, desencadeados ambos pelas condições de penúria que suporta o sertanejo, mas confrontadas pelas singularidades do se mundo cultural (RIBEIRO, 1995, $\mathrm{p}$ 354-355).
\end{abstract}

Quanto ao fanatismo religioso, Darcy Ribeiro certamente se referia especialmente ao movimento de Canudos, ocorrido com o final do Império no Brasil por conta da chegada do modelo republicano. Foi esse um dos motes de inspiração da obra do citado escritor Euclides da Cunha que, em seu livro mais conhecido, relatou o movimento de Canudos, liderado por Antonio Conselheiro. Foi uma mobilização contra a República e em defesa do Império e do retorno da família real. Eram milhares de sertanejos muito pobres, sofridos e esquecidos pelo governo brasileiro; eram a realidade de um país que, apesar de propor-se uma república federativa, nem sequer conhecia ou lembrava-se dos grupos sociais que viviam distantes de grandes cidades e da capital brasileira na época, Rio de Janeiro.

Conforme explica Lúcia Lippi Oliveira (1998), o desejo maior de Euclides da Cunha era denunciar uma situação de retrocesso da vida dessas pessoas e de integrar o sertão à vida nacional.

\begin{abstract}
$\mathrm{Na}$ primeira parte de Os Sertões, Euclides mostra o sertão como um território estranho, um vazio, um hiato, um espaço em branco a ser preenchido. $\mathrm{Na}$ indiferença dos brasileiros por sua própria terra estaria a raiz desta ignorância e desde desconhecimento do território sertanejo. $O$ sertão seria mesmo a prova da existência de fronteiras internas que ameaçavam a nacionalidade. Para Euclides era mister tornar a totalidade do espaço territorial um espaço nacional (OLIVEIRA, 1998, p. 5).
\end{abstract}

Dessa forma, o que se torna evidente é uma diferenciação entre o sertão e a cidade, interior e litoral, o que era tido como mundo civilizado e o mundo retrógrado, ambos convivendo em um mesmo território nacional (OLIVEIRA, 1998). Todavia, o foco posto em cheque nesse artigo trata de uma região denominada como sertão, mas que dista espacialmente do sertão nordestino. Trata-se de outra área do país, o interior do estado de São Paulo que nas narrativas, textos, relatos e documentos dos fins do século XIX e primeiras décadas do século $X X$ usam comumente a denominação para se referir ao interior paulista.

Nesse território, a figura do bandeirante foi preponderante para o desbravamento de terras desconhecidas pela colônia portuguesa nos séculos $\mathrm{XVII}$ e XVIII. "O movimento das bandeiras constitui a principal experiência de fronteira na história brasileira” (OLIVEIRA, 1998, p. 7). Foram responsáveis pelo 
desbravamento de terras completamente desconhecidas dos primeiros governantes e que eram, quase que em sua totalidade, ocupada por tribos indígenas. Ficaram conhecidos pela pecha de dizimadores de índios, ao mesmo tempo em que foram elevados à categoria de grandes responsáveis pela construção da nacionalidade, e a trajetória desses homens sempre esteve intimamente relacionada à história de São Paulo no período colonial (OLIVEIRA, 1998).

Já mais recente, no entanto, foi a atuação de outros desbravadores no estado paulista nos finais do século XIX e início do século $X X$. Com o desenvolvimento da cafeicultura e com a expansão de ferrovias rumo ao interior paulista e movidos pelo espírito do progresso, do desenvolvimento e do avanço da economia agrícola, esse novos bandeirantes, por assim dizer, cortavam picadas no meio das matas e levavam o progresso aos confins do estado. Em relatos e documentos da Comissão Geográfica e Geológica de São Paulo (CGG), na primeira década do século $X X$, o termo sertão é comumente utilizado para se referir a esse espaço inóspito e desconhecido que era o interior paulista.Assim como seus habitantes: também eram estranhos, selvagens, bravios. $O$ homem do sertão paulista "é sempre um 'outro' geográfico, alteridade que nos define por ser aquilo que não somos - ou não queremos ser. Assim o 'sertão' paulista era entendido como o lugar, imaginário e real, a ser transformado pela modernidade do novo século XX" (FIGUERÔA, 2008, p. 764).

Tratava-se de um período em que se combatia com veemência a miscigenação no país, caráter que, muitas vezes, foi entendido como sendo formador de um povo degenerado. Entretanto, quando se fala dos bandeirantes paulistas, essa miscigenação é fator de elevação, de superioridade, pois originou um homem forte, desbravador, corajoso e motivador do avanço rumo às áreas desconhecidas e ocupadas apenas pela presença indígena. $O$ objetivo era ir além das fronteiras que isolavam toda essa imensidão de terras ocupadas pela Mata Atlântica. "Além" significa distância espacial, marca um progresso, promete o futuro", como explica Homi Bhabha (2010, p. 23), e era pensando em uma futura província de São Paulo que se desejava adentrar aos territórios do interior paulista.

Dessa forma, "certas áreas paulistas foram classificadas como 'sertão desconhecido', não por serem de fato inexploradas, mas por terem configurações tais que as tornavam indesejáveis para os rumos pretendidos para a província" (SANTOS, 2016, p. 198). Tal denominação em uso funcionava para legitimar "a implantação de novas formas produtivas e de ocupação dessas terras, mais afins aos planos econômicos e políticos da elite dirigente de São Paulo". Parafraseando Laura de Mello e Souza, Amália Santos explica que o que ocorria era um processo de “'autoenobrecimento' dos bárbaros sertanistas” (SANTOS, 2016, p. 198).

(...) a forma encontrada pelos próprios paulistas para desfazerem-
-se do dualismo e, principalmente, das imagens de homens vis e
desleais foi o forjamento de uma nobreza, desde o século XVIII,
quando a capitania perde sua autonomia, e a declaração de nobreza
é o "mito disponível para usos ideológicos" Para o bom resulta-
do desse processo, podemos crer que era indispensável expurgar
não apenas o que havia de sertanista nesses homens, mas
o próprio caráter sertanejo do espaço da capitania ${ }^{4}$ e pos-
teriormente província de São Paulo. Assim, no início do século XIX,
o território oficial paulista vai sendo adequado ao desenvolvimen-
to econômico pretendido, para o qual a ideia do sertão selvagem

4 Grifos do autor. 
em simbiose com os paulistas não era mais interessante. $O$ sertão, antes dominado, era agora declarado desconhecido dos habitantes planaltinos. (SANTOS, 20 I6, p. 198).

Dessa forma, torna-se evidente a percepção de que os sertões, seja em qual região brasileira se pense, eram áreas pouco exploradas e que, especialmente por conta de interesses econômicos e agrícolas diversos, acabaram por ser incorporados à Colônia - no caso do Brasil Imperial - ou à República, após 1889. A proposta até aqui era de elucidar brevemente o que tem sido debatido nas Ciências Sociais brasileiras o que foi e é entendido como sertão e sobre quem nele vive. Necessário, agora, revelar quem era o outro, o sertanejo, e as práticas, bem como a cultura matéria, que o rodeava.

\section{Estudos sobre folclore, o sertão e seus habitantes}

Não é incomum na literatura acadêmica específica encontrar as questões sobre os sertões e suas populações inseridas nos chamados estudos folclóricos. Houve, durante as primeiras décadas do século $X X$, muitos debates e até uma depreciação de trabalhos e pesquisas sobre folclore. Autores que se identificavam como folcloristas foram, muitas vezes, rechaçados pelo universo acadêmico, cujos trabalhos eram tidos como não-científicos, desprovidos de método e de pesquisas alinhadas com teorias sociais e históricas.

O interesse pelo folclore foi trazido à tona com a atuação de intelectuais como o modernista Mário de Andrade e de Paulo Duarte, frente ao Departamento Municipal de Cultura em São Paulo, criado por ele na década de 1930. A maior preocupação era manter registros da cultura brasileira. Com base na "retórica da perda", o objetivo das pesquisas desenvolvidas por folcloristas desse período, ligado ao movimento gerado por Mário de Andrade, era de registrar a cultura brasileira que, acreditava-se, estava se esvaindo (DINIZ, 20I0, p. I34). Houve naquele momento uma aproximação dos trabalhos sobre folclore com os propósitos da pesquisa etnográfica da Antropologia, tanto que um curso sobre etnografia chegou a ser ministrado na Sociedade de Etnografia e Folclore, ligada ao Departamento de Cultura de São Paulo, pela esposa de Claude Lévi-Strauss, Dina Lévi-Strauss (DINIZ, 20I0).

Tratava-se de um momento importante para a consolidação da Sociologia e da Antropologia no Brasil.A primeira escola foi a Escola de Sociologia e Política de São Paulo (ESP) - fundada em 1933 - e a Universidade de São Paulo inaugurou o curso de Sociologia em 1934, com a presença de vários profissionais estrangeiros, como Claude Lévi-Strauss, Roger Bastide, Donald Pierson e Herbert Baldus.

Baldus fora etnógrafo do Museu Paulista, pertencente à Universidade de São Paulo. Fora professor também na ESP e tivera como aluno Alceu Maynard Araújo, que estudara sobre pesquisa etnográfica. Maynard Araújo fora, depois, professor também da ESP e contribuiu sobremaneira para a formação das chamadas coleções sertanejas do Museu Paulista. Brevemente, tais coleções são o mote da pesquisa de pós-doutorado que vem sendo desenvolvida junto ao Museu de Arqueologia e Etnologia da Universidade de São Paulo. Há uma preocupação em conhecer e identificar os doadores e formadores dessas coleções. É por meio da trajetória social desses objetos que se pode compreender as redes que foram estabelecidas e que compreendiam pesquisadores, etnógrafos, folcloristas, professores, populações locais, governantes, ou seja, um universo de 
relações sociais, culturais e materiais que levam à compreensão a respeito do sujeito sertanejo.

As coleções sertanejas, então, inicialmente ficavam no Museu Paulista. Na década de 1980 começou a construção do Museu de Arqueologia e Etnologia, dentro da cidade universitária, e para lá parte dessas coleções e as coleções etnográficas foram levadas no início dos anos de 1990. Atualmente os dois museus possuem coleções com a denominação de sertanejas.

A pesquisa documental é fundamental para conhecer melhor como se deu a formação dessas coleções. Atas administrativas, correspondências, listagens de objetos são fontes importantes para, primeiramente, identificar o que é entendido por sertanejo e, secundariamente, compreender o que é esse universo material que dá pistas sobre o modo de vida do homem do sertão paulista. Todavia, vale destacar mais uma vez que o interesse por tais objetos só se deu como fruto de um momento histórico e social do qual fizeram parte intelectuais e instituições, que se preocupavam em registrar a cultura, especialmente no tocante a esse artigo, a do paulista. "Junto a esse impulso modernizador havia o desejo de se recuperar o passado paulista, de se conhecer melhor a história da cidade e do Estado que se transformavam, de expor sua faceta mais bandeirante e "quatrocentona ",5 (RUBINO, p. 493).

Dessa forma, começa a se delinear o perfil sobre esse outro, o sertanejo. Primeiramente era o indivíduo que vivia fora da vila de São Paulo (no caso do Império) ou da capital paulista após a proclamação da República. Tratava-se de homens e mulheres que viviam em confins do estado, em meio à Mata Atlântica, em territórios ainda povoados por vários grupos indígenas. No entanto, o sertanejo não era índio; eram identidades diferentes. Índios, ao contrário, eram alvos dos sertanejos. Muitos desses eram afeitos à caça de grupos nativos, ou por desejo de posse das terras dos grupos, ou simplesmente pela dizimação e extermínio de sociedades indígenas que não eram bem quistas, visto que não contribuíam para o crescimento e desenvolvimento do estado.

Esse dado, inclusive, foi discutido por Funari e Mourad (2016), quando falam a respeito do papel do primeiro diretor do Museu Paulista, Hermann von lhering:

Com o fim da monarquia em 1889, o Rio de Janeiro continuou sendo a capital, até 196I, mas os poderes econômicos e políticos foram em direção ao oeste e ao sul, já que a República era dominada pela aristocracia paulista, os primeiros cultivadores de café e posteriormente os primeiros industriais. $O$ etos da elite paulista prestava menos atenção à nobre imagem do índio, já que historicamente os paulistas - apesar de eles próprios serem descendentes dos nativos e portugueses - foram inimigos jurados dos indígenas e eram conhecidos como "caçadores de índios". Nas primeiras décadas do século $X X$, o movimento contra os indígenas acentuou-se e a coleta de relíquias arqueológicas não era particularmente comum. A curadoria de material arqueológico no mais ativo dos museus deste período, o Museu Paulista em São Paulo, foi colocada sob a orientação de Hermann von llhering, que defendia a extinção dos indígenas brasileiros. Von Ilhering era um arquétipo curador do império; enquanto coletava relíquias das tribos indígenas ele, ao mesmo tempo, advogava pela destruição de seus descendentes ainda vivos (...). Após a restauração do governo civil em 1945, relíquias pré-históricas, deixadas no escuro durante o apogeu da ideologia nacionalista voltaram à cena, particularmente com o humanista $\mathrm{e}$

5 Quatrocentona é o adjetivo que foi adotado por famílias paulistas para se autoenobrecerem, isto é, alegavam que estavam no Brasil desde a fundação de São Paulo, em I554. O termo foi muito utilizado no século XX, justamente quanto São Paulo completou seu IV Centenário em 25 de janeiro de 1954. 
ativista político Paulo Duarte que, apesar de ser membro da elite paulista, defendia pela primeira vez a necessidade de proteger as modestas relíquias pré-históricas. (FUNARI; MOURAD, 2016, p. 26-27).

Ou seja, ser paulista não era sinônimo de ser nativo, indígena. No entanto, ainda que se rechaçasse a descendência indígena, os paulistas descendentes de grupos sociais desde o século $\mathrm{XVI}$ eram sim fruto de miscigenação entre portugueses e indígenas. Mas, ainda no século XVI, entra em cena a participação africana na formação do povo brasileiro. Documentos dos primeiros colonizadores narravam que o índio não era afeito ao trabalho, e iniciativas de tentar escravizar grupos indígenas não teriam sido bem sucedidas. Para a exploração agrícola da nova colônia, Portugal trouxe para a colônia sul-americana a força-de-trabalho africana para, principalmente, atuar na monocultura da cana-de-açúcar no Nordeste brasileiro.

As coleções sertanejas localizadas no Museu de Arqueologia e Etnologia e no Museu Paulista da Universidade de São Paulo coloca, entre suas listagens, objetos tais como: pilões de jacarandá, tipitis, miniaturas de embarcações, violas, espada de Congo, bandeiras de santos católicos, lamparinas, máscara da Folia de Reis, ex-votos, objetos de terreiros de macumba, bonecas de pano e cerâmica paulista, palmatória para surrar escravos, etc. No âmbito da pesquisa em andamento, contabilizou-se até o momento coleções que contam com, mais ou menos, 950 objetos. Quase que na totalidade são objetos de uso para o trabalho e doméstico, objetos de origem afro-brasileira e, raramente, objetos da tradição material indígena.

Deduz-se dessas observações da documentação do Museu Paulista que a imagem do sertanejo era, quase que na totalidade, embasada sobre as tradições portuguesa e africana. Ser sertanejo compreendia uma descendência provável de sujeitos originários do continente africano e do império português. Mas não de matrizes indígenas. Esse fato dialoga claramente com análises supra-citadas que apontam no sentido de um ódio e abominação às tradições nativas do Brasil, em detrimento das tradições africanas, por exemplo que, apesar de em sua totalidade abraçar sujeitos que eram escravos, ainda assim, eram provavelmente menos aversivos culturalmente que os povos indígenas do mundo novo.

Apesar de a tradição de nativos brasileiros ser bastante negada, a tradição africana se faz muito presente nas coleções sertanejas. As coleções revelam, então, um indivíduo que traz em seu sangue as origens portuguesa e africana; que se utiliza de práticas sociais de origens branca, do português, e negra, do escravo africano. Isso fica bem evidente, por exemplo, nos trabalho de Alceu Maynard Araújo. Em boa parte das pesquisas que realizou, ele buscou apreender o espírito das tradições paulistas acerca da cultura do sertanejo: músicas, danças, bailados, dentre outras 6 .

"Os artistas modernos estão voltando ao primitivo, procurando identificar-se com as manifestações populares coletivas e é sem dúvida um tema nacionalizador" (Araújo, 1952, p. 7). O objetivo de registrar a cultura, seja em seu aspecto material ou imaterial, era fazer com que aquilo que era tido como tradicional fosse preservado no presente, para servir de referência para futuras gerações. Não se questionava como a coleta de dados fora feita; se houve espólio ou não de objetos. Simplesmente a preocupação girava em torno de uma necessidade que esses intelectuais demonstravam de fazer guarda e conservação de tudo que dissesse a um passado do paulista. 
Coleções são uma sistematização da cultura humana; organizam e classificam o mundo que nos rodeia. Atualmente, há um movimento generalizado de buscar um processo de descolonização das coleções e dos museus. Isso significa um processo de transformação na maneira como se expõem tais coleções, especialmente as etnográficas, bem como atuam no sentido de descaracterizar os elementos que indiquem uma atitude por parte dos museus de expor o outro como sendo exótico, diferente, inferior, etc. De fato, trata-se de uma postura relevante para que não se faça do outro, no caso o sertanejo, um objeto de museu, estereotipando-o; mas será que tem razão de ser esquecermos o que foi o processo de colonização e de dominação desses povos? Não faz parte da história de colônias e de impérios o processo de expansão para o novo mundo? Qual a vantagem em descolonizar, esquecendo ou talvez até negando um passado que realmente existiu?

Não é essa, todavia, a postura no MAE-USP, nem em tantos outros museus no mundo afora. Há uma crítica museológica de peso que faz com que curadores, museólogos e profissionais de museus sejam muito mais cautelosos quanto às narrativas que constroem, fazendo como muitas vezes se vê de, ao invés de fazer do outro um objeto de museu, trazer esse outro para compor junto ao museu? ${ }^{7}$.

O sertanejo, nas observações feitas até então, se mostra uma construção social; ele não era uma realidade, mas sim uma idealização a respeito dos homens e mulheres que viviam no sertão. Esses sujeitos não eram indígenas. Eram sobreviventes, exploradores, desbravadores, vindos de vários cantos. Muitos até descendiam também de grupos indígenas, mas essa característica era camuflada, a fim de mostrar um sujeito forte e destemido, adjetivos que não eram atribuídos aos povos nativos. $\mathrm{Na}$ verdade, o sertanejo era um homem simples, mas trabalhador, corajoso. São pessoas que viviam fora de cidades, eram homens do mundo rural ou de pequenas vilas. E que tinham atrativos, cultural e materialmente falando, que eram merecedores de serem trazidos à capital, São Paulo, para serem estudados e para servirem de documentação sobre um modo de vida peculiar.

\section{Considerações finais}

Todo objeto de museu é ele também um documento. Vasta é a reflexão sobre essa categorização ${ }^{8}$, e todas elas caminham no sentido de mostrar que o documento busca uma verdade ou relevar uma veracidade naquilo que traz em seu corpo ou conteúdo. Documento não é só o documento de papel; ele é até imaterial, e pode ser tridimensional, como o objeto museológico.

A partir do momento em que os objetos das coleções sertanejas adentram o museu, eles deixam para trás uma trajetória social cotidiana, para se tornarem objetos seletos e que adquirem outra funcionalidade. No museu, uma

7 É o caso da exposição temporária que acontece no MAE-USP atualmente, "Resistência já: Fortalecimento e união das culturas indígenas - Kaingang, Guarani Nhandewa e Terena. A proposta foi de dar voz aos grupos para que eles mesmos falassem de suas culturas, trazendo-os para dentro do museu e compondo juntamente com eles a curadoria e a seleção e organização dos objetos expostos.Vide o link da exposição: http://www.vmptbr.mae.usp.br/modules/exposicmae/content.php?topic=exposicoes-temporarias-ano-2017\&id=77\&page=kaingang-guarani-nhandewa-e-terena-resistencia-ja

8 Em especial, destaca-se aqui a área da Ciência da Informação, que é por excelência o campo que mais debate e reflete sobre o documento. Para saber mais sobre o tema, a tese de Rodrigo Rabello (2009) é uma referência importante e que sistematiza claramente o desenvolvimento dessa reflexão científica. 
panela não será usada para cozinhar; nesse espaço, a panela se torna uma fonte para se saber de que material ela foi feita, como as pessoas cozinhavam nela, a que grupos ou tempo histórico ela se relaciona, etc.

Sendo assim, quando se constituem coleções denominadas sertanejas, objetos se transmutam em documentos que falam o que era o sertanejo do início do século $X X$. $O$ caráter é tão preponderante, que muitas vezes se recorre ao museu para saber quem era o índio, o negro escravo, do que ir a outras fontes ou até mesmo falar com as pessoas que realmente são pertencentes a esses grupos para se saber o que foi a realidade de seus antepassados. Com o sertanejo acontece a mesma coisa, a partir do momento que essa nomenclatura para pelos portões de um museu: ali dentro, o sertanejo é essencialmente aquilo que os objetos apontam que ele era, como comia, rezava, trabalhava, festejava, etc. Não se trata, todavia, de culpabilizar o museu por estereotipar o sertanejo, e sim é esse fato consequência de um modo de vida, que é praxe do mundo ocidental, em classificar tudo que está à nossa volta, pois quando classificamos, organizamos e apreendemos tudo que nos rodeia.

Quando o sertanejo é classificado pelos pesquisadores e pelos objetos musealizados, dá-se um reforço àquilo que é próprio do mundo ocidental que é a prática de documentar; o sertanejo é conhecido por meio de documentos que dizem a seu respeito, o que implica em verdades que são concebidas para produzirem conhecimento. Essa é a máxima científica de qualquer ciência, na verdade, documentar é necessário para que haja um registro de tudo que foi produzido e pensado pelo ser-humano. $O$ que nos faz também pensar que, caso não tivesse havido essa preocupação em guardar a cultura material dos grupos do sertão, talvez nem mesmo soubéssemos da existência deles. Entretanto, é importante saber que se trata de uma construção, e não de uma máxima inquestionável a respeito do sertanejo.

Esse outro era diferente de seus observadores, por isso faziam esses últimos o uso pertinente da etnografia como forma de pesquisa para acessar e apreender a cultura do outro. Ainda que fossem, talvez, semelhantes em alguns pontos, a relação de alteridade preponderava, fazendo com que os grupos sertanejos fossem, em um primeiro momento, vistos como aglomerações sociais distintas da do pesquisador, o que fazia com que esses etnógrafos vissem a necessidade de registrar a respeito desse modo de vida sertanejo. E, certamente, para o sertanejo esses profissionais vindo de cidades grandes também eram estranhos. Aí tinha-se estabelecida a relação necessária de estranhamento, ou seja, de admiração e susto perante um modo de vida tão diverso. Para encerrar, Catulo da Paixão Cearense, cantou as lamúrias do sertanejo que sai do seu lugar de origem e vai para a cidade, onde sofre pela falta de um céu estrelado e enluarado, que nas metrópoles é ofuscado pelas luzes artificiais. E cantou:

Não há, oh gente, oh não

Luar como este do sertão

A gente fria

Desta terra sem poesia

Não se importa com esta lua

Nem faz caso do luar

Enquanto a onça

Lá na verde da capoeira

Leva uma hora inteira

Vendo a lua derivar 
As Representações do Outro na investigação das coleções sertanejas do MAE - USP

\section{Referências}

ARAÚjO, Alceu M. Documentário Folclórico Paulista. São Paulo: Prefeitura de São Paulo/Depto. de Cultura - Divisão do Arquivo Histórico, 1952.

. Folclore Nacional: festas, bailados, mitos e lendas. Vol. I. São Paulo: Ed. Melhoramentos, 1964.

. Folclore Nacional: ritos, sabença, linguagem, artes e técnicas. Vol. III. São

Paulo: Ed. Melhoramentos, 1967.

BHABHA, Homi K. O local da cultura. Belo Horizonte: Editora UFMG, 2010.

DINIZ, Igor Mello. Os estudos de folclore e as Ciências Sociais no Brasil (19301940). Revista Habitus. Rio de Janeiro: IFCS/UFRJ;Vol. 8, N. 2, 20I0. Disponível em: www.habitus.ifcs.ufrj.br.Acesso em 5 Jun. 2019.

FIGUERÔA, Silvia F. de M. 'Batedores da ciência' em território paulista: expedições de exploração e a ocupação do 'sertão' de São Paulo na transição para o século XX. História, Ciências, Saúde - Manguinhos. Rio de Janeiro. V. I5, n. 3, p. 763-777, jul-set 2008. Disponível em: http://www.scielo.br/scielo. php?pid=S0 I 04-597020080003000 I 0\&script=sci_abstract\&tlng=pt. DOI: http:// dx.doi.org/I0.I590/SO I04-597020080003000I0.Äcesso em I8 set. 2018.

FUNARI, Pedro p.; MOURAD, Tamima O. Curadores do Império: patrimônio como pilhagem colonialista. Revista Heródoto. Guarulhos/SP: Unifesp. V. 0I, n. 01. Março, 2016. p. 19-36. Disponível em: https://www.researchgate.net/publication/326025I58_CURADORES_DO_IMPERIO_PATRIMONIO_COMO_PILHAGEM_COLŌNIALISTA. DOI: I0.31669/herodoto.v lil.37. Acesso em $\overline{5}$ jul. 2017.

OLIVEIRA, Lúcia Lippi.A conquista do espaço: sertão e fronteira no pensamento brasileiro. História, Ciência, Saúde - Manguinhos. Rio de Janeiro, Vol V (suplemento), julho 1998. Disponível em: http://www.scielo.br/scielo.php?pid=S0 I04-597019980004000 I I \&script=sci_abstract\&tlng=pt. DOI: http://dx.doi. org/I0.I590/SO I04-5970I9980004000I I.Acesso em I8 set.20I8.

RABELLO, R. A face oculta do documento: tradição e inovação no limiar da Ciência da Informação. Marília/SP: Unesp: FFC/DPGCI. Disponível em: http://www. marilia.unesp.br/Home/Pos-Graduacao/Cienciadalnformacao/Dissertacoes/ rabello_r_do_mar.pdf Acesso:Jan. 2012).

RIBEIRO, Darcy. O povo brasileiro: evolução e o sentido do Brasil. São Paulo: Companhia das Letras, 1995.

RUBINO, Clube de pesquisadores: a Sociedade de Etnografia e Folclore e a Sociedade de Sociologia. In MICELI, Sérgio (org.). História das Ciências Sociais no Brasil.Vol. 2. São Paulo: Ed. Sumaré, 1995.

SANTOS, Amália C. dos. As concepções de "território" na pesquisa histórica: o sertão paulista. Revista do Instituto de Estudos Históricos. n. 63, abril 2016, p. I8I20I. Disponível em: http://www.scielo.br/pdf/rieb/n63/0020-3874-rieb-63-0I8I. pdf. DOI: http://dx.doi.org/I0.I I606/issn.23 I6-90IX.v0i63pI8I-20I.Acesso I8 set. 2018. 